\title{
Correspondence
}

\section{Impact of improved perinatal care on the causes of death}

\section{Sir,}

We would like to comment on the paper by Barson et al and the commentary by Dr Addy. ${ }^{1}$

The authors themselves and the distinguished commentator apparently find their data confusing. That may be in part because they have not given themselves and the readers enough data to make a useful analysis.

If the authors' purpose is to evaluate the overall causes of perinatal death, they seem, sadly, to have missed the significance of perhaps the most important piece of data in their paper-why were they delivering twice as many very low birthweight babies (less than $1.5 \mathrm{~kg}$ ) in 1981 than 1976. Were these spontaneous labours or ill women who had to be delivered, or was the increase purely and simply a measure of the number of high risk women likely to deliver sick, very low birthweight infants who were transferred to their unit. An answer to this question is essential before attempting to analyse the data in the way they have, since it is unjustified to draw conclusions about the efficacy of neonatal care when the number of low birthweight babies doubles, if no data is given on the incidence of the various conditions from which babies may die.

Concentrating, however, on infants weighing between 1.0 and $1.5 \mathrm{~kg}$, what their data clearly shows (Table 4 in their analysis) is that by 1981 very few infants weighing 1.0 to $1.5 \mathrm{~kg}$ were allowed to die in utero and there has been a highly significant reduction in perinatal mortality (667 per 1000 to 220 per 1000). Of those delivered alive the numbers dying of immaturity or asphyxia (both of which, in live born babies at this birthweight, mean by and large the same thing-hyaline membrane disease plus intraventricular haemorrhage) remained constant at five to nine babies per year. This sounds like first class obstetrics backed up by first class neonatology and is a powerful vindication for the centralisation of perinatal care as occurs in Manchester.

With that interpretation there is no connundrum; the message is clear.

J A DAvis, G M Gandy
C J Morley, AND N R C RoBerton
Addenbrooke's Hospital and Rosie Maternity Hospital,
Hill Road,
Cambridge

Sir,

Although we appreciate the importance of good obstetric care and prompt resuscitation at birth, we must take issue with Barson et $a^{1}$ for relegating the role of neonatal intensive care in improving the perinatal mortality rate at St Mary's Hospital, Manchester. Firstly, the findings at necropsy do not necessarily reflect the efficacy of neonatal intensive care-nor was Wigglesworth's classification of perinatal deaths ${ }^{2}$ designed for that purpose. Secondly, the authors base their conclusions on data from 1976 to $1981-$ only after full intensive care was established at this hospital. That is analogous to studying the effect of the compulsory wearing of car seat belts while ignoring the years before legislation was introduced. Before 1976 preterm babies who established breathing at birth but who subsequently deteriorated with respiratory distress or apnoeic attacks were not routinely offered mechanical ventilation. Instead they were compassionately treated in a way appropriate to the facilities available - they were given warmth, oxygen, and intravenous fluids.

We now summarise our data on 527 babies who were liveborn at this hospital from 1970 to 1983 and whose birthweights were between 1001 and $1500 \mathrm{~g}$. We feel uneasy about the way Barson et al have interpreted deaths from 'asphyxia', 'miscellaneous causes', and 'immaturity', but for the purpose of comparison we have used definitions similar to theirs. We have, therefore, excluded babies who were unresponsive to resuscitation at birth; those who were successfully resuscitated at birth after what was clearly birth asphyxia, but who died soon after without manifesting respiratory distress; those in whom severe intracranial trauma was found at necropsy; those with lethal malformations; and those who died from 'miscellaneous causes' in which category Dr Barson and his colleagues include hydrops fetalis, necrotising enterocolitis, septicaemia, and meningitis. There remain 468 'immature' babies.

From 1970 to 1975 the survival rates of immature babies who weighed between 1001 and $1250 \mathrm{~g}(\mathrm{n}=58)$ and 1251 to $1500 \mathrm{~g}(\mathrm{n}=89)$ were $46 \cdot 6 \%$ and $75 \cdot 3 \%$ respectively. From 1976 to 1983 the corresponding survival rates were $80 \cdot 6 \%$ $(\mathrm{n}=134, \mathrm{P}<0.005)$ and $92.0 \%(\mathrm{n}=187, \mathrm{P}<0.003)$ respectively. How far can the improved survival be attributed to the introduction of neonatal intensive care including mechanical ventilation? The most common clinical problems in these babies were respiratory distress and recurrent apnoea and we have chosen these as 'markers' for the need for intensive care and a potential requirement for mechanical ventilation. Although the annual number of inborn immature babies was greater from 1976 to 1983 compared with earlier years, the incidence of respiratory distress and recurrent apnoea from 1970 to 1983 showed no trend and ranged from $76.0 \%$ to $84.6 \%$ in babies who weighed 1001 to $1250 \mathrm{~g}$ and $49.0 \%$ to $71.4 \%$ in those weighing 1251 to $1500 \mathrm{~g}$.

The striking improvement in the survival rate of babies with respiratory distress or recurrent apnoea after the introduction of intensive care in 1976 is shown in Fig. 1. We do not undertake mechanical ventilation lightly and we firmly believe that most babies to whom we offered mechanical ventilation would have died without it. If our data are re-analysed assuming that those babies who received mechanical ventilation would have died without 


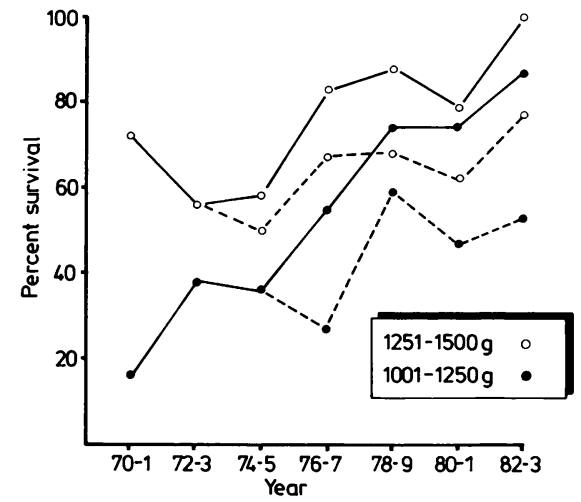

Fig. 1 Survival rates (alive at discharge) of inborn babies weighing 1001 to $1250 \mathrm{~g}$ and $1251 \mathrm{to} 1500 \mathrm{~g}$ from 1970 to 1983.)

it, the improvement in the survival rates from 1976 to 1983 is not so striking (Fig. 1). Indeed the overall survival of babies weighing 1251 to $1500 \mathrm{~g}$ from 1976 to $1983(68 \cdot 5 \%)$ would not have been significantly greater than it was from 1970 to $1975(60 \cdot 0 \%)$. The contribution of mechanical ventilation to the survival rates of babies is summarised in Fig. 2.

We agree with Barson et al that good quality neonatal intensive care influences obstetrical management and leads to elective preterm delivery of high risk fetuses, thereby reducing the risk of stillbirth from asphyxia. Indeed, we submitted that idea as written and oral evidence to the House of Commons Social Services Committee in $1980 .^{3}$ There are great pitfalls in using information from perinatal necropsy surveys as a basis for auditing neonatal care. Audit requires a mutlidisciplinary approach including the

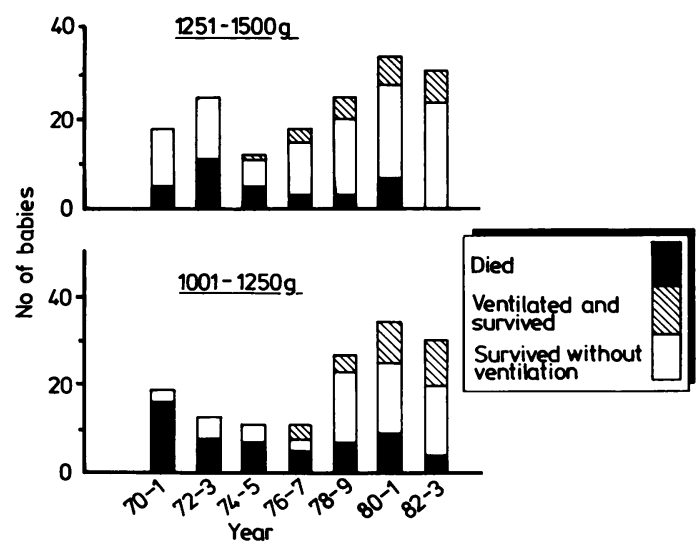

Fig. 2 Number of inborn babies with respiratory distress or recurrent apnoea weighing 1001 to $1500 \mathrm{~g}$ who died, survived after receiving mechanical ventilation, and survived without mechanical ventilation. assessment of neurodevelopmental handicap in surviving babies. We recently drew attention to the improving prognosis of low birthweight babies after the introduction of intensive care at this hospital (British Paediatric Association Annual Meeting, 1984). We conclude that neonatal intensive care has improved the survival of immature babies with established respiratory distress or recurrent apnoea irrespective of any beneficial influence it might have had on babies asphyxiated at birth. Those who might be tempted to direct their resources solely towards resuscitation of asphyxiated babies while relegating continuing neonatal care must be warned.

\section{References}

' Barson AJ, Tasker M, Lieberman BA, Hillier VF. Impact of improved perinatal care on the causes of death. Arch Dis Child 1984;59:199-207.

${ }^{2}$ Wigglesworth JS. Monitoring perinatal mortality. A pathophysiological approach. Lancet 1980;ii:684-6.

${ }^{3}$ Second report from the House of Commons Social Services Committee, session 1979-1980. Perinatal and neonatal mortality. Volume IV. London, HMSO: 500.

D G Sims ANd M L Chiswick North Western Regional Perinatal Centre, St Mary's Hospital, Whitworth Park, Manchester M13 OJH

\section{Food allergy and infantile colitis}

Sir,

We read with interest the important paper by Jenkins et al ${ }^{1}$ on the role of food allergy as a major cause of infantile colitis. The authors state "we have shown that food allergic colitis . . . accounts for most, if not all, children who present in the first year of life suffering from colitis.'

This has not been our experience at St Bartholomew's Hospital and the Queen Elizabeth Hospital for Children.

Table Details of 11 children aged under 1 year presenting with colitis and response to elimination diet

\begin{tabular}{|c|c|c|c|}
\hline $\begin{array}{l}\text { Case } \\
\text { No }\end{array}$ & Diagnosis & $\begin{array}{l}\text { Age at onset } \\
\text { of symptoms }\end{array}$ & $\begin{array}{l}\text { Responded to } \\
\text { elimination } \\
\text { diet }\end{array}$ \\
\hline 1 & $\begin{array}{l}\text { Indeterminate colitis and } \\
\text { subtotal colectomy }\end{array}$ & $1 w k$ & No \\
\hline 2 & Indeterminate colitis & 3 wks & No \\
\hline 3 & Food allergic colitis & $5 \mathrm{wks}$ & Yes \\
\hline 4 & Food allergic colitis & 6 wks & Yes \\
\hline 5 & Indeterminate colitis & $10 \mathrm{wks}$ & No \\
\hline 6 & Food allergic colitis & 3 mths & Yes \\
\hline 7 & Indeterminate colitis & $4 \mathrm{mths}$ & No \\
\hline 8 & $\begin{array}{l}\text { Behcet's colitis and } \\
\text { subtotal colectomy }\end{array}$ & $4 \mathrm{mths}$ & No \\
\hline 9 & $\begin{array}{l}\text { Behcet's colitis and } \\
\text { subtotal colectomy }\end{array}$ & $5 \mathrm{mths}$ & No \\
\hline 10 & Indeterminate colitis & $6 \mathrm{mths}$ & No \\
\hline 11 & Food allergic colitis & 7 mths & Yes \\
\hline
\end{tabular}

